\title{
ANÁLISE DE ESTOQUE DE UMA LOJA DE AUTOPEÇAS ATRAVÉS DA SIMULAÇÃO COMPUTACIONAL: UM ESTUDO DE CASO
}

\author{
Alanna Mirella G. de Carvalho (UNIVERSIDADE POTIGUAR) alannamirella@ hotmail.com \\ Raisa Bezerra de Lima (UNIVERSIDADE POTIGUAR) raisablima@ hotmail.com \\ Rafael Chaves de Sousa Ichihara (UNIVERSIDADE POTIGUAR) rafael.ichihara@ unp.br
}

\section{Resumo}

Este trabalho propõe melhorar o nível de serviço de uma empresa de autopeças por meio da gestão de estoques dos produtos mais demandados. Os produtos em estudo foram selecionados por meio da classificação $\mathrm{ABC}$ e suas disponibilidades em estoque avaliadas com base no consumo mensal em um modelo de simulação computacional desenvolvido no software Arena ${ }^{\circledR}$. A partir dos resultados da simulação, um estoque mínimo foi determinado para cada produto com objetivo de reduzir reposições não programadas e atendimentos emergenciais. Além disso, foram avaliados e determinados pontos de estocagem ótimos para reduzir o deslocamento necessário para acessar estes produtos. O nível de estoque obtido a partir da análise da simulação computacional - considerando um grau de atendimento de $90 \%$ - foi satisfatório, pois não houveram demandas não atendidas no modelo de simulação computacional. Constatou-se também que os novos pontos de estocagem obtidos no modelo promoveram uma redução de 1370 metros de deslocamento mensal para acessar aos produtos em análise.

Palavras-chave: (Simulação computacional. Gestão de estoque. Nível de serviço).

\section{Introdução}

As empresas, principalmente de pequeno porte, sofrem grandes impactos com um mercado que enfrenta constantes transformações. Para manter um ajuste viável entre objetivos, habilidades, recursos e oportunidades, o planejamento estratégico se faz essencial, de modo a dar forma aos negócios e produtos da organização (KOTLER, 2000).

À vista disso, uma alternativa para a redução de custos é a prática correta da gestão de estoques. Tal gerenciamento pode ter grande influência no retorno sobre o ativo (SLACK et al, 2015). Entretanto, poucas empresas organizam seu estoque da forma mais adequada, sendo necessária a utilização de ferramentas que possam auxiliar nesse processo. Uma ferramenta amplamente útil para a avaliação de dados e tomada de decisões é a curva $\mathrm{ABC}$, sendo um método adequado para planejar a distribuição dos produtos a partir do volume de vendas (POZO, 2010). 
Dentro deste contexto encontra-se a empresa Renoservice Autopeças, localizada em Natal/RN e atua no ramo de peças e serviços automotivos. Após autorização pelo proprietário para realização do estudo, verificou-se que a empresa possui estoques excessivos de alguns produtos e que estes estão localizados em pontos distantes, dificultando o acesso pelos balconistas.

Diante do exposto, o objetivo deste trabalho é desenvolver um modelo de simulação computacional para identificar alternativas de melhoria na disponibilidade dos produtos mais relevantes da loja com base no consumo mensal destes produtos dentro do período de análise.

Com base nos resultados do modelo, será possível determinar um nível de estoque mínimo de segurança desses produtos, bem os pontos de estocagem mais adequados, ou seja, os locais em que possam ser facilmente acessados pelos funcionários da empresa.

A solução de problemas em qualquer empresa pode implicar em investimentos e tecnologias, além de custos adicionais com tempo de projeto e execução. Tal decisão deve ser realizada de forma cautelosa e assertiva de modo a minimizar o impacto destes custos.

Dessa forma, a utilização da simulação computacional de processos é uma importante ferramenta de análise e suporte à tomada de decisões, visto que o comportamento de um processo real pode ser estudado em diferentes cenários sem necessidade de intervenção prévia nos processos e os resultados serão tão próximos da realidade quanto o modelo representar o processo real.

\section{Referencial teórico}

\subsection{Nível de serviço logístico}

Ballou (2006) relaciona o nível de serviço com o fluxo de bens serviços e o tempo necessário para atender aos requisitos do cliente, sendo assim, um somatório das atividades fundamentais para gerar um grau de atendimento eficiente. Dessa maneira, os componentes estratégicos do nível de serviço envolvem o relacionamento com o cliente, atuando no gerenciamento de suas expectativas; e relacionamento entre distribuição e gestão de estoques e de localização.

Para Lambert (1998), o nível de serviço não determina somente se os atuais clientes irão perdurar, mas também de estabelecer quantos clientes em potencial se tornarão clientes efetivamente. 
Para possibilitar o atendimento ao mercado com maior ou menor nível de atendimento, Pozo (2010) propõe comparar valores através do coeficiente de grau de atendimento (Tabela 1).

Tabela 1 - Valores do coeficiente $\mathrm{k}$ para percentuais de grau de atendimento.

\begin{tabular}{cccc}
\hline $\begin{array}{c}\text { Grau de } \\
\text { Atendimento }\end{array}$ & $\boldsymbol{k}$ & $\begin{array}{c}\text { Grau de } \\
\text { Atendimento }\end{array}$ & $\boldsymbol{k}$ \\
$(\mathbf{\%})$ & & $(\boldsymbol{\%})$ & \\
\hline $\mathbf{5 5}$ & 0,126 & 80 & 0,842 \\
$\mathbf{6 0}$ & 0,253 & 85 & 1,036 \\
$\mathbf{6 5}$ & 0,385 & 90 & 1,233 \\
$\mathbf{7 0}$ & 0,524 & 95 & 1,645 \\
$\mathbf{7 5}$ & 0,674 & 99,9 & 3,090 \\
\hline
\end{tabular}

Fonte: Adaptado de Pozo (2010)

\subsection{Gestão e custo de estoques}

Para Slack et al (2015), estoque é um termo utilizado para descrever o acúmulo de matérias, clientes ou informações que fluem por meio de processos ou redes. $\mathrm{O}$ inventário pode ser definido como a acumulação de materiais físicos e filas são acumulações de clientes. Segundo os autores, o gerenciamento dessas acumulações pode ser denominado como gestão de estoque.

O estoque mínimo é definido como uma quantidade mínima de peças que deve haver no estoque para suprir eventuais mudanças de demanda, atrasos de fornecedores ou problemas com lotes de compra. Prioriza-se um estoque mínimo que otimize os recursos e minimize os custos de modo a atender ocasiões previsíveis no plano de produção e a política de nível de atendimento (POZO, 2010).

Segundo Pozo (2010), o estoque mínimo é determinado conforme a equação:

$$
\text { Emín }=\delta \bullet k
$$

Tal que:

Emín = Estoque mínimo;

$\delta=$ Desvio padrão de consumo; 
$k=$ coeficiente de grau de risco.

\subsection{Curva ABC}

Viana (2002) define a curva ABC como um instrumento que possibilita a identificação de itens que necessitam tratamento e atenção adequados no seu gerenciamento. Ele acrescenta que a implementação da classificação ABC pode ocorrer por tempo de reposição, valor de demanda, inventário, aquisições ou classificação por valor de consumo, sendo esta última a predominante.

Segundo Martins e Laugeni (2005), a curva ABC se subdivide em três classes:

a) Classe A: representa 10 a $20 \%$ dos itens em que o valor de consumo está entre 50 a $80 \%$. Geralmente são os itens mais importantes e devem ser cuidados com atenção.

b) Classe B: representa os itens intermediários, cerca de 20 a $30 \%$ dos itens e possuem valor de consumo em média de 20 a $30 \%$.

c) Classe C: possui um grande número de itens, representando mais de $50 \%$ e possuindo valor de consumo médio entre 5 e $10 \%$.

\subsection{Simulação computacional}

Segundo Kelton et al (2007), a simulação computacional se refere a métodos utilizados para estudar uma variedade ampla de modelos reais através de avaliação numérica feita por meio de um software capaz de imitar as características das operações do sistema.

Santos et al estabelece que a pesquisa operacional (PO) é utilizada para resolver problemas reais através do desenvolvimento de modelos matemáticos e lógicos. Desse modo, a simulação computacional é uma técnica da PO que auxilia à tomada de decisão, agindo como ferramenta para avaliar soluções. Tal técnica se apresenta como um ambiente inteligente, reproduzindo o que acontece no mundo físico através de processos virtuais, se caracterizando por uma grande capacidade de aprendizado e inovação.

Para a construção do modelo de simulação computacional por eventos discretos, o software utilizado será o Arena ${ }^{\circledR}$. Através do seu ambiente gráfico, é possível a modelagem de processos, fluxos e análise dos resultados obtidos em gráficos, estatísticas e relatórios. 
As entidades são os elementos básicos da modelagem no Arena ${ }^{\circledR}$. Elas representam as pessoas, os objetos ou transações que se movem ao longo do sistema. As estações de trabalho definem onde será realizado cada processo. O fluxo é a representação do caminho a ser percorrido pela entidade ao longo das estações. (PRADO, 2003).

Os módulos Arena® utilizados neste trabalho estão descritos no Quadro 1.

Quadro 1 - Descrição dos módulos do Arena® utilizados no trabalho.

\begin{tabular}{|c|c|c|c|}
\hline Módulo & Função & Módulo & Função \\
\hline Create & $\begin{array}{l}\text { Introduz as entidades no modelo em } \\
\text { intervalos de tempo definidos. }\end{array}$ & Variable & $\begin{array}{l}\text { Define os valores iniciais das } \\
\text { variáveis do modelo. }\end{array}$ \\
\hline Seize & $\begin{array}{c}\text { Ocupa um recurso e faz a entidade } \\
\text { aguardá-lo. }\end{array}$ & Record & $\begin{array}{l}\text { Coleta estatísticas nos pontos } \\
\text { do modelo escolhidos. }\end{array}$ \\
\hline Resource & $\begin{array}{l}\text { Relaciona todos os recursos } \\
\text { utilizados no modelo. }\end{array}$ & Release & $\begin{array}{c}\text { Libera um recurso ocupado } \\
\text { anteriormente. }\end{array}$ \\
\hline Schedule & $\begin{array}{l}\text { Define a programação de } \\
\text { exploração e duração dos recursos. }\end{array}$ & Decide & $\begin{array}{c}\text { Permite a tomada de decisões } \\
\text { baseado em condições } \\
\text { estabelecidas. }\end{array}$ \\
\hline Assign & $\begin{array}{l}\text { Associa valores e parâmetros às } \\
\text { variáveis e atributos de entidades. }\end{array}$ & Process & $\begin{array}{c}\text { Representa uma ação no } \\
\text { sistema que leve um tempo } \\
\text { para ser cumprida. }\end{array}$ \\
\hline Delay & $\begin{array}{l}\text { Causa uma espera, fazendo a } \\
\text { entidade aguardar no módulo até } \\
\text { que o tempo seja transcorrido. }\end{array}$ & Dispose & $\begin{array}{l}\text { Retira as entidades do modelo, } \\
\text { encerrando o sistema. }\end{array}$ \\
\hline
\end{tabular}




\section{Metodologia}

Neste trabalho, o trajeto seguido para sua realização está baseado em um estudo de caso, método no qual são levados em consideração: a amostragem, a coleta e análise de dados, com abordagem específica para a empresa em estudo.

A estratégia de pesquisa de um estudo de caso, de acordo com Yin (2001), trata de contextos reais, em especial, aqueles em que não se tem o controle dos fenômenos. Desta forma, os passos para execução do estudo de caso são:

a) Identificar os produtos mais relevantes para estudo utilizando a curva $\mathrm{ABC}$ com base no consumo mensal;

b) Medir as distâncias dos produtos mais relevantes dos pontos de estocagem atual e pontos alternativos ao balcão de atendimento;

c) Identificar o fluxograma do processo de atendimento e coletar informações pertinentes:

- Intervalo de chegada de clientes;

- Consumo mensal por produto relevante;

- Tempo de atendimento nos postos de trabalho.

d) Construir o modelo de simulação computacional no Arena®;

e) Analisar os resultados da simulação computacional para definir os pontos de estocagem e quantidades mínimas de produtos em inventário;

f) Analisar o nível de ocupação dos colaboradores no modelo de simulação computacional.

\section{Desenvolvimento}

\subsection{Identificação dos produtos relevantes}

No banco de dados da Renoservice Autopeças, identificou-se 5 itens como mais relevantes com base no consumo mensal no período de janeiro a outubro de 2019, conforme Tabelas Tabela 2 e Tabela 3. 
Tabela 2 - Consumo mensal dos produtos.

\begin{tabular}{ccccccc}
\hline Consumo & $\begin{array}{c}\text { Óleo de } \\
\text { Motor }\end{array}$ & $\begin{array}{c}\text { Vela de } \\
\text { Ignição }\end{array}$ & $\begin{array}{c}\text { Filtro de } \\
\text { Óleo }\end{array}$ & $\begin{array}{c}\text { Água } \\
\text { Destilada }\end{array}$ & $\begin{array}{c}\text { Kit } \\
\text { Amortecedor }\end{array}$ & $\begin{array}{c}\text { Outros } \\
\text { Produtos }\end{array}$ \\
\hline Total & 10335 & 4439 & 2608 & 2204 & 1995 & 46864 \\
Médio & 1034 & 444 & 261 & 220 & 200 & 4686 \\
Desvio- & 102 & 89 & 25 & 31 & 22 & 729 \\
Padrão & & & & & & \\
\hline
\end{tabular}

Fonte: Banco de dados da Renoservice Autopeças. Dados tratados pelos autores (2019)

Tabela 3 - Percentual de consumo dos produtos.

\begin{tabular}{ccc}
\hline Produtos & Consumo Total & Percentual Consumo \\
\hline Óleo de Motor & 10335 & $15,1 \%$ \\
Vela de Ignição & 4439 & $6,5 \%$ \\
Filtro de Óleo & 2608 & $3,8 \%$ \\
Água Destilada & 2204 & $3,2 \%$ \\
Kit Amortecedor & 1995 & $2,9 \%$ \\
Demais Produtos & 46864 & $68,5 \%$
\end{tabular}

Fonte: Banco de dados da Renoservice Autopeças. Dados tratados pelos autores (2019)

Os produtos em análise correspondem à aproximadamente $30 \%$ dos produtos mais consumidos conforme curva $\mathrm{ABC}$, esquematizado no Gráfico 1. 
Gráfico 1 - Curva ABC dos produtos da Renoservice Autopeças.

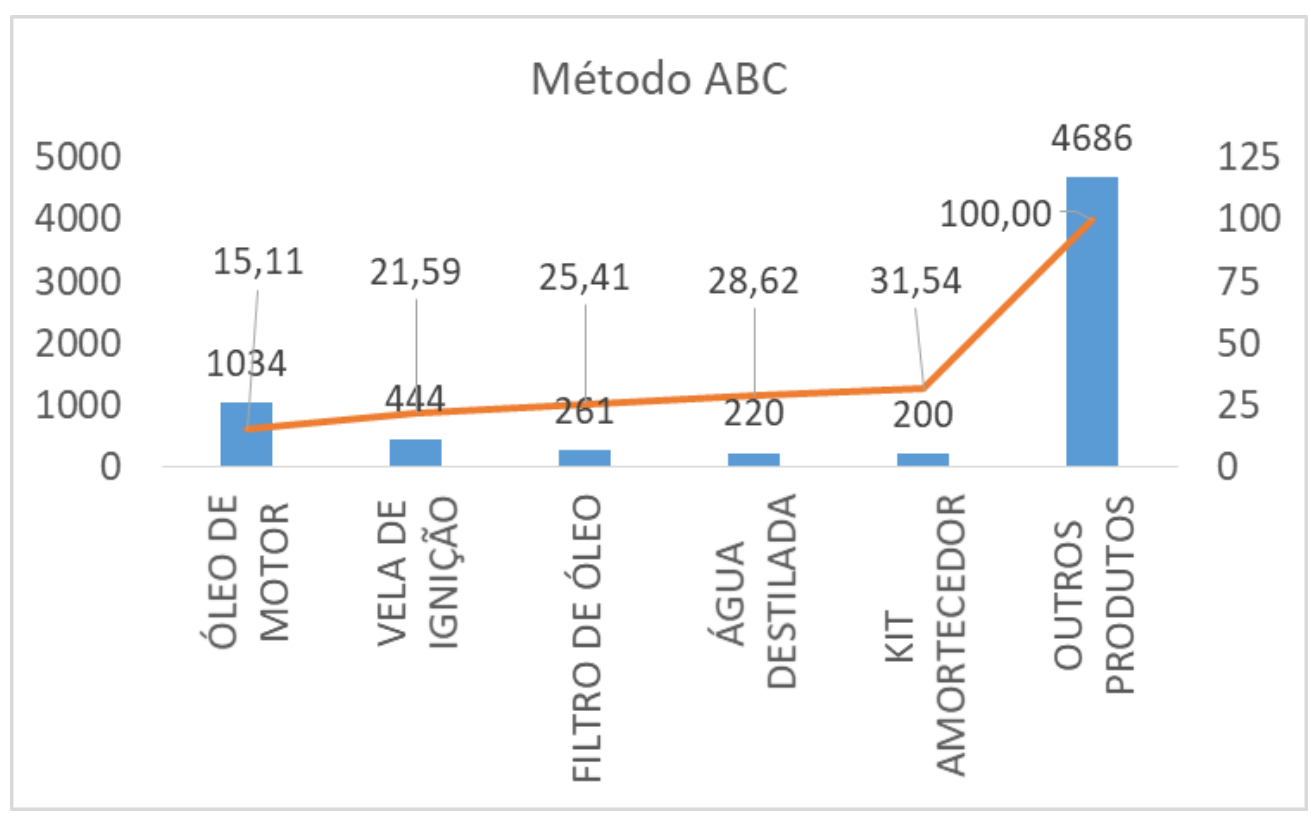

Fonte: Banco de dados da Renoservice Autopeças. Dados tratados pelos autores (2019)

\subsection{Medição dos pontos de estocagem}

Com a identificação dos produtos mais relevantes, foi elaborada uma planta baixa para melhor visualização dos locais onde se situam esses produtos, assim como dos pontos alternativos para alocação dos itens (Figura 1).

Figura 1 - Localização dos produtos relevantes e dos pontos alternativos de estocagem.

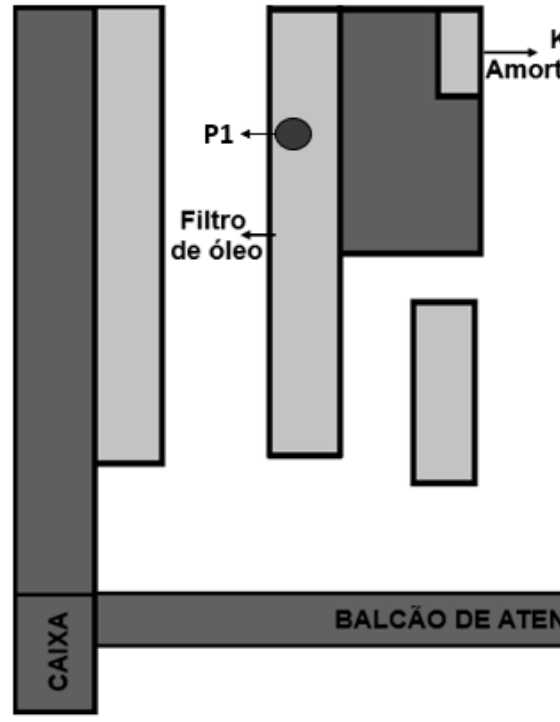

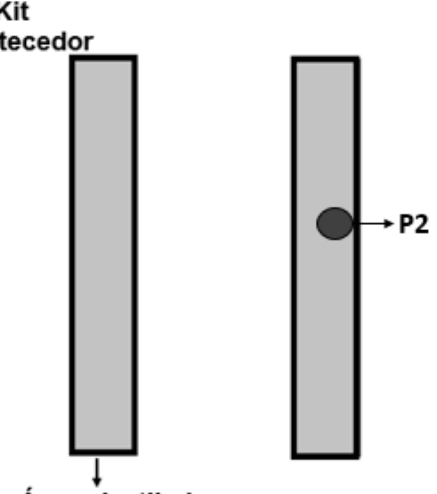

Água destilada
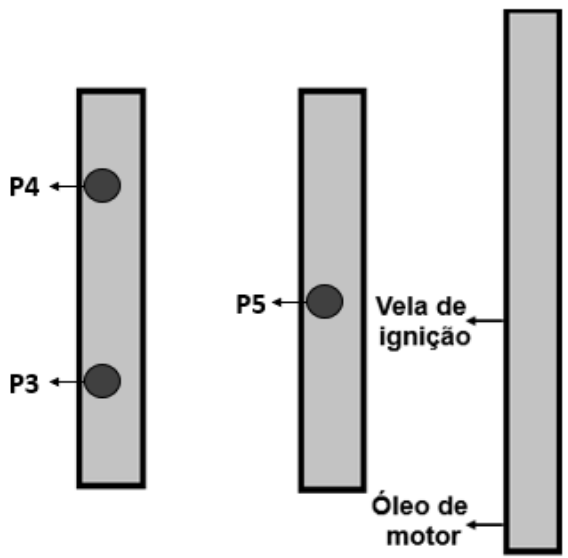

Legenda:

Pontos alternativos

Fonte: Autores (2019) 
As distâncias atuais dos produtos relevantes em estudo foram obtidas a partir de um ponto de medição central no balcão de atendimento, conforme Tabela 4.

Tabela 4 - Distâncias atuais dos produtos em estudo ao balcão de atendimento.

\begin{tabular}{cc}
\hline Produtos & $\begin{array}{c}\text { Distância ao balcão } \\
\text { (metros) }\end{array}$ \\
\hline Óleo de motor & 4,6 \\
Vela de ignição & 6,6 \\
Filtro de óleo & 5,2 \\
Água destilada & 0,6 \\
Kit amortecedor & 6,6 \\
\hline
\end{tabular}

Fonte: Autores (2019)

Também foram medidas as distâncias de cada um dos pontos alternativos até o ponto de medição do balcão de atendimento, conforme Tabela 5 .

Tabela 5 - Distância do balcão aos pontos alternativos de estocagem.

\begin{tabular}{cc}
$\begin{array}{c}\text { Pontos } \\
\text { Alternativos }\end{array}$ & $\begin{array}{c}\text { Distância ao balcão } \\
\text { (metros) }\end{array}$ \\
\hline Ponto 1 & 6,5 \\
Ponto 2 & 4,6 \\
Ponto 3 & 3,8 \\
Ponto 4 & 5,5 \\
Ponto 5 & 6,6 \\
\hline
\end{tabular}

Fonte: Autores (2019) 


\subsection{Processo de atendimento dos clientes}

O processo contém basicamente duas atividades: atendimento no balcão de pedidos e pagamento no caixa, conforme Figura 2.

Figura 2 - Fluxograma do processo de atendimento da Renoservice Autopeças.

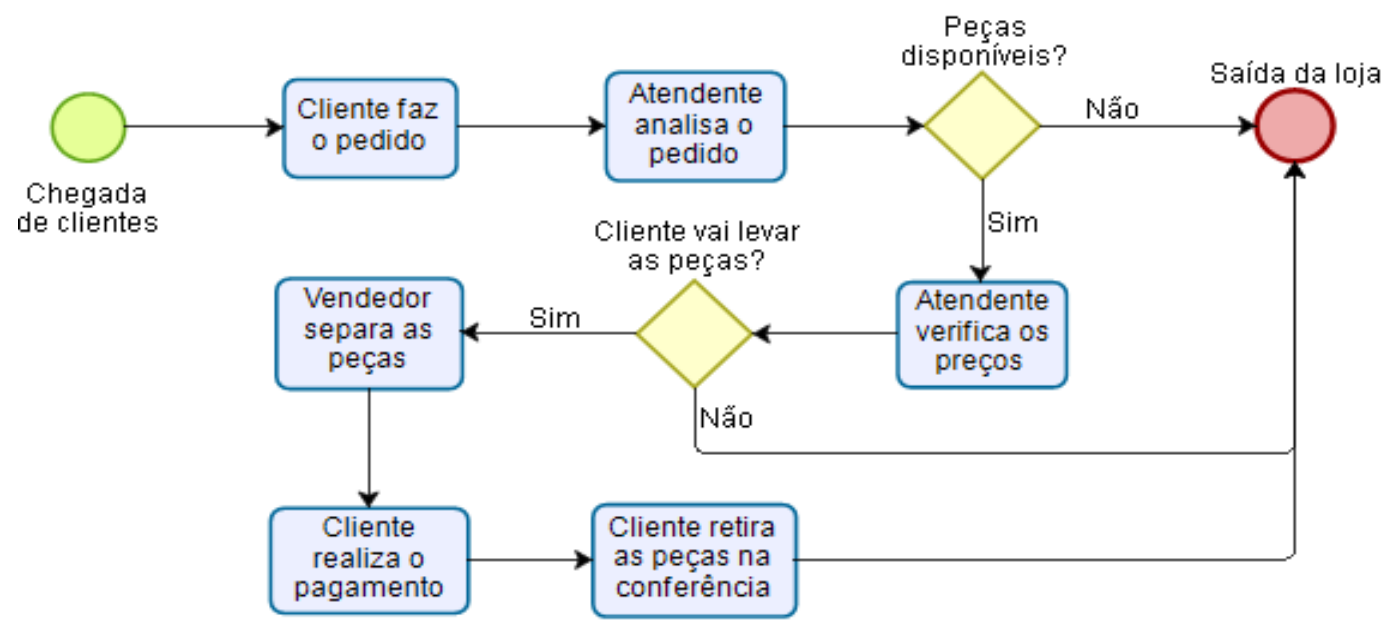

Fonte: Autores (2019)

O fluxograma da Figura 2 servirá como base para coleta de dados dos parâmetros do modelo de simulação computacional.

Para determinação do intervalo entre chegadas dos clientes, foram cronometrados tempos durante dez dias, de acordo com a Tabela 6.

Tabela 6 - Tempo médio entre chegadas dos clientes.

\begin{tabular}{cc}
\hline Data & $\begin{array}{c}\text { Média entre chegadas } \\
\text { (minutos) }\end{array}$ \\
\hline $01 / 08 / 2019$ & 5,42 \\
$02 / 08 / 2019$ & 5,24 \\
$03 / 08 / 2019$ & 6,14 \\
$05 / 08 / 2019$ & 7,04 \\
$06 / 08 / 2019$ & 6,00 \\
$07 / 08 / 2019$ & 6,97 \\
$08 / 08 / 2019$ & 5,59
\end{tabular}




\begin{tabular}{cc}
$09 / 08 / 2019$ & 6,00 \\
$10 / 08 / 2019$ & 4,66 \\
\hline Média geral & 5,90 \\
\hline
\end{tabular}

Fonte: Autores (2019)

O tempo médio para atender os clientes e desvio padrão foram levantados a partir dos dados coletados durante sete dias (Tabela 7).

Tabela 7 - Tempo atendimento no balcão (minutos).

\begin{tabular}{ccc}
\hline Data & Média de Atendimento & Desvio-Padrão \\
\hline $07 / 10 / 2019$ & 3,73 & 1,38 \\
$08 / 10 / 2019$ & 4,65 & 1,27 \\
$09 / 10 / 2019$ & 4,43 & 1,35 \\
$10 / 10 / 2019$ & 4,22 & 1,80 \\
$11 / 10 / 2019$ & 4,13 & 1,62 \\
$14 / 10 / 2019$ & 4,07 & 1,47 \\
$15 / 10 / 2019$ & 4,50 & 1,57 \\
\hline Média geral & 4,25 & 1,49 \\
\hline
\end{tabular}

Fonte: Autores (2019)

Foram coletados também os tempos médios e desvio padrão do atendimento no caixa (Tabela 8).

Tabela 8 - Tempo de atendimento no caixa (minutos).

\begin{tabular}{ccc}
\hline Data & Média de Atendimento & Desvio-padrão \\
\hline $18 / 11 / 2019$ & 1,33 & 0,66 \\
$19 / 11 / 2019$ & 2,32 & 0,54 \\
$20 / 11 / 2019$ & 1,27 & 0,94
\end{tabular}




\begin{tabular}{lll}
$21 / 11 / 2019$ & 1,89 & 0,73 \\
$22 / 11 / 2019$ & 2,16 & 0,65 \\
$23 / 11 / 2019$ & 2,33 & 1,02 \\
\hline Média Geral & 1,88 & 0,76 \\
\hline
\end{tabular}

Fonte: Autores (2019)

\subsection{Desenvolvimento do modelo no software Arena ${ }^{\circledR}$}

O modelo de simulação no Arena® (Figura 3) foi construído de acordo com os dados dos processos desde a chegada do cliente até a sua saída. Dentro de cada módulo, foram implantados os dados coletados na empresa.

Figura 3 - Modelo de simulação Arena ${ }^{\circledR}$ da Renoservice Autopeças.

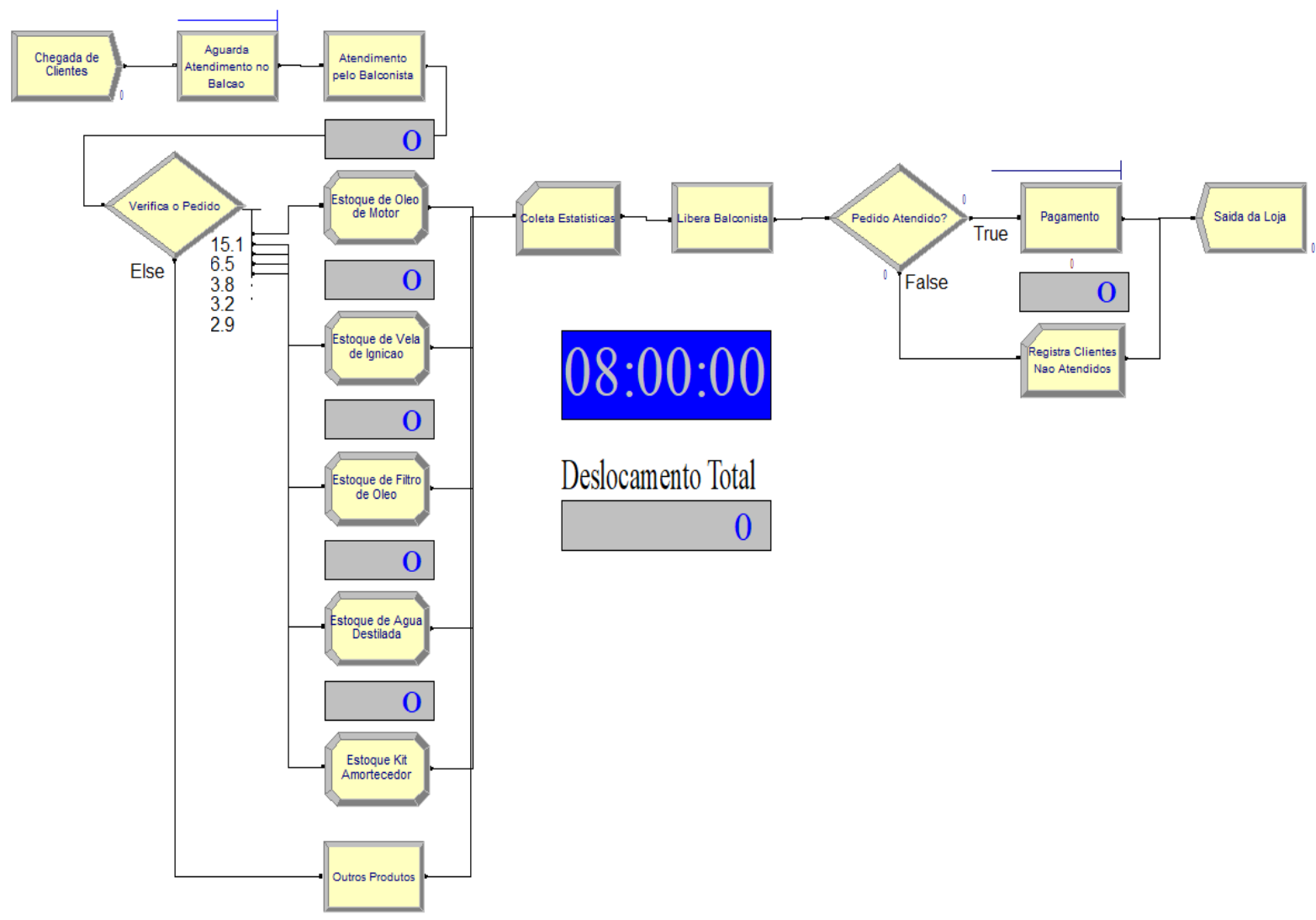

Fonte: Autores (2019)

Para representar a escolha do produto pelo cliente, foi utilizado o módulo "Decide" (Figura 4), onde foram definidas as probabilidades de escolha de cada item, de acordo com os percentuais 
calculados (Tabela 3). Caso sejam escolhidos os demais produtos da empresa, que correspondem aos 68,5\% restantes, o fluxo seguirá pelo caminho “Else” (Figura 3).

Para configurar a demanda e o deslocamento até os produtos, foi utilizado um módulo "Assign" para cada item. Para o primeiro produto (Figura 5) foi inserida a variável "Oleo_Motor. Como o consumo diário deste item varia entre 3 e 4 unidades por cliente, foi adotada uma distribuição uniforme para representar esta demanda, de forma que estes limites têm igual probabilidade de ocorrer.

Figura 4 - Configuração do módulo Decide no Arena®.

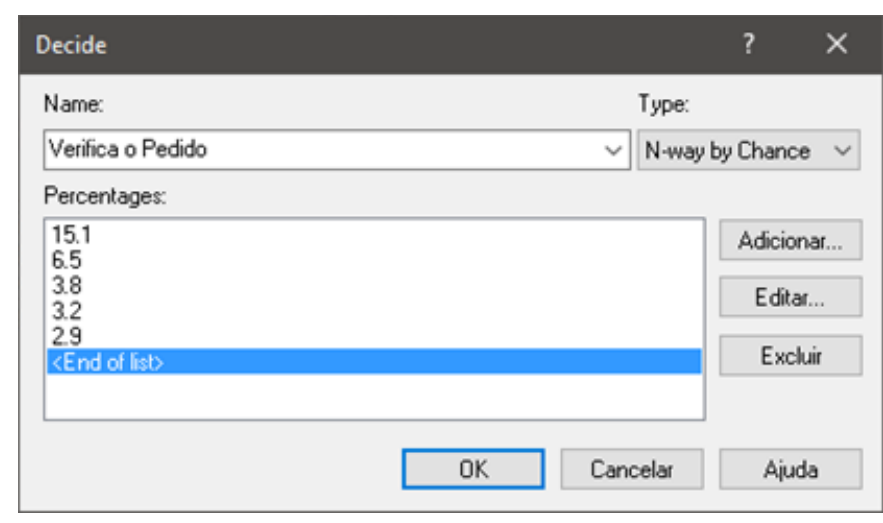

Fonte: Autores (2019)

Também foi inserido um atributo (Nao_Atendido) para identificar as demandas não atendidas. Para o produto em questão, ela recebe o valor do teste lógico (Oleo_Motor < 0). Esta lógica retorna 1 quando o resultado é verdadeiro, ou seja, quando não há óleo de motor em estoque. Caso contrário, o atributo "Nao_Atendido" recebe valor 0 , indicando que o cliente foi atendido. Ainda no módulo "Assign", foi adicionado um atributo que também obedecerá a uma lógica (Figura 5) para contabilizar o deslocamento em metros nos casos da demanda atendida. Se o item estiver disponível, a distância (Tabela 4) será somada à contagem da variável "Deslocamento_Total" (Figura 3). Desse modo, a distância de cada produto será multiplicada por dois, para representar o percurso de ida e volta. 
Figura 5 - Configuração do módulo Assign no Arena®.

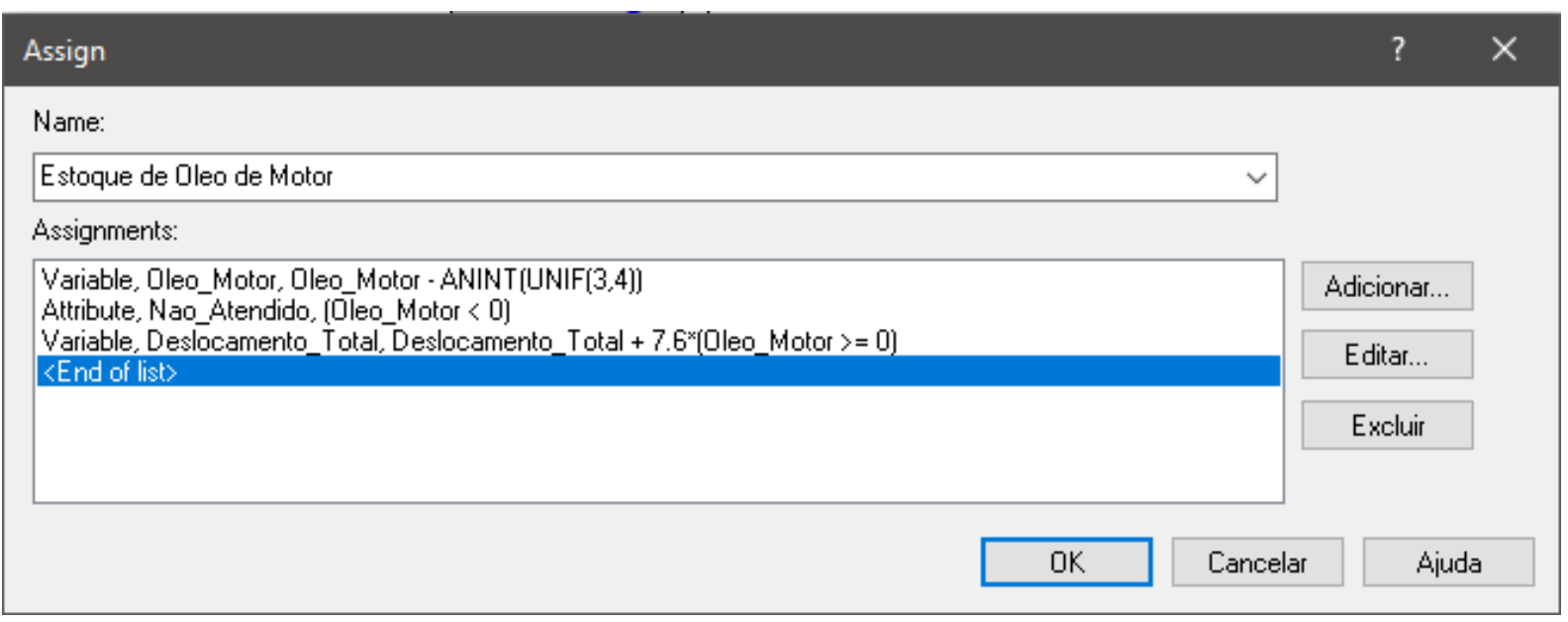

Fonte: Autores (2019)

As configurações da vela de ignição, do filtro de óleo, da água destilada e do kit amortecedor seguirão a mesma lógica, resumidas na Tabela 9.

Tabela 9 - Configuração do consumo e distância dos demais produtos em estudo.

\begin{tabular}{lcc}
\hline PRODUTOS & CONSUMO & DESLOCAMENTO \\
\hline Vela de ignição & Vela_Ignicao -4 & $13.2 *($ Vela_Ignicao $>=0)$ \\
Filtro de óleo & Filtro_Oleo -1 & $10.4 *($ Filtro_Oleo $>=0)$ \\
Água destilada & Agua_Destilada - ANINT $(\operatorname{UNIF}(3,4))$ & $1.2 *($ Agua_Destilada $>=0)$ \\
Kit amortecedor & Kit_Amortecedor - ANINT(UNIF $(1,2))$ & $13.2 *($ Kit_Amortecedor $>=0)$ \\
\hline
\end{tabular}

Fonte: Autores (2019)

Na realização do pagamento, foi incluído um "Process" (Figura ), sendo na sua lógica, selecionada a ação "Seize Delay Release”. Para esse módulo foi adotada uma distribuição de probabilidade normal com média de 1,88 minutos e desvio padrão de 0,76 minutos, de acordo com a coleta listada na Tabela 8 . 
Figura 6 - Configuração do módulo Process no Arena®.

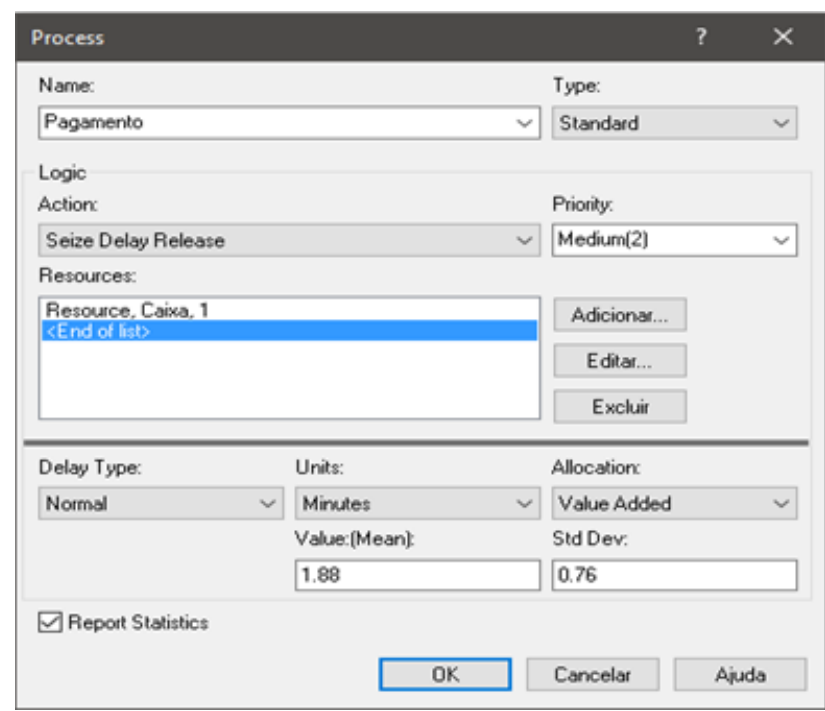

Fonte: Autores (2019)

\section{Resultados}

\subsection{Primeira simulação}

Para dar início à primeira simulação, os estoques iniciais de cada produto foram ajustados para a média de demanda do período de janeiro a outubro de 2019, de acordo com a Tabela 2, e as distâncias utilizadas de cada item até o balcão foram os valores presentes na Tabela 4.

O período de simulação do modelo foi de 24 dias, uma vez que a empresa funciona de segunda à sexta em expediente normal (22 dias úteis) e aos sábados meio expediente. Como em um mês costumam haver 4 sábados, foram adicionados 2 dias para simular esse comportamento. A partir disso, o modelo foi simulado e o relatório Arena ${ }^{\circledR}$ das variáveis e atributos inseridos nos módulos "Record" ("User Specified" - "Tally"), nível de ocupação dos colaboradores ("Resource" - "Usage") e tempos de fila nos processos ("Queue" - "Waiting Time") são esquematizados na

Figura .

Assim, os resultados obtidos na primeira simulação foram:

a) Os estoques do óleo de motor, da vela de ignição e da água destilada ficaram negativos em 266, 152 e 52 itens, respectivamente;

b) Os estoques do filtro de óleo e do kit amortecedor excederam em 154 e 98 itens, respectivamente; 
c) De todos os clientes que entraram na loja, 129 não realizaram o pedido por falta de estoque;

d) O deslocamento total dos balconistas no período foi de 6256 metros.

Figura 7 - Síntese do relatório da primeira simulação do modelo Arena®.

\section{User Specified}

\section{Tally}

\begin{tabular}{lrrrr} 
Expression & Average & Half Width & $\begin{array}{r}\text { Minimum } \\
\text { Value }\end{array}$ & $\begin{array}{r}\text { Maximum } \\
\text { Value }\end{array}$ \\
\hline Deslocamento_Balconistas & 3772.21 & (Correlated) & 0.00 & 6256.00 \\
Estoque_Agua_Destilada & 89.2791 & (Correlated) & -52 & 220.00 \\
Estoque_Filtro_Oleo & 206.94 & (Correlated) & 154.00 & 261.00 \\
Estoque_Kit_Amortecedor & 144.01 & (Correlated) & 98.0000 & 200.00 \\
Estoque_Oleo_Motor & 337.90 & (Correlated) & -266 & 1034.00 \\
Estoque_Vela_Ignicao & 136.05 & (Correlated) & -152 & 444.00
\end{tabular}

\section{Counter}

\begin{tabular}{lr} 
Count & Value \\
\hline Pedidos_Sem_Estoque & 129.00
\end{tabular}

\section{Resource}

\section{Usage}

\begin{tabular}{lrrrr} 
Number Busy & Average & Half Width & $\begin{array}{c}\text { Minimum } \\
\text { Value }\end{array}$ & $\begin{array}{c}\text { Maximum } \\
\text { Value }\end{array}$ \\
\hline Balconista & 0.7367 & 0,033980112 & 0.00 & 4.0000 \\
Caixa & 0.3045 & (Correlated) & 0.00 & 1.0000
\end{tabular}

\section{Queue}

Time

\begin{tabular}{lrccc} 
Waiting Time & Average & Half Width & $\begin{array}{r}\text { Minimum } \\
\text { Value }\end{array}$ & $\begin{array}{r}\text { Maximum } \\
\text { Value }\end{array}$ \\
\hline Atendimento no Balcao.Queue & 0.08243981 & (Correlated) & 0.00 & 5.3949 \\
Pagamento.Queue & 0.4062 & 0,062940780 & 0.00 & 8.3347
\end{tabular}

Fonte: Autores (2019).

Quanto ao nível de ocupação dos recursos, nota-se que os balconistas ficaram ocupados 73,67\% do tempo de simulação, ao passo que o caixa ficou $30,45 \%$ do tempo ocupado. Este último valor está associado à especificação do modelo, que explora os produtos mais relevantes que representam aproximadamente $30 \%$ do total demandado. 
Por fim, verifica-se que o tempo de espera em fila dos clientes foi baixo, com valor médio de 0,08 minutos e tempo máximo de 5,39 minutos para o atendimento no balcão. Para o atendimento no caixa, o tempo médio de espera foi de 0,41 minutos, com valor máximo de 8,33 minutos.

A partir do relatório de filas, nota-se que os recursos têm alta disponibilidade para os produtos relevantes. O relatório de recursos apresenta um nível de ocupação acima de 70\%. Portanto, não há alterações a serem realizadas nos recursos.

\subsection{Segunda Simulação}

Na segunda simulação, deve-se corrigir a disponibilidade mensal dos produtos por meio da subtração dos valores iniciais e finais de estoque de cada produto, obtidos na primeira simulação. Em seguida, soma-se o resultado com o estoque mínimo, obtido pelo produto do desvio-padrão do consumo (Tabela 2) pelo coeficiente do grau de atendimento desejado para a loja.

O grau de atendimento foi definido junto ao proprietário da loja de autopeças. Para garantir alto nível de serviço, adotou-se $90 \%$ de grau de atendimento, que implica em $k=1,233$. Assim, têm-se:

a) Nível de estoque do óleo de motor:

$1034-(-266)+102 \cdot 1,233 \approx 1425$ unidades;

b) Nível de estoque da vela de ignição:

$444-(-152)+89 \cdot 1,233 \approx 705$ unidades;

c) Nível de estoque do filtro de óleo:

$261-(-154)+25 \cdot 1,233 \approx 137$ unidades;

d) Nível de estoque da água destilada:

$220-(-52)+31 \cdot 1,233 \approx 310$ unidades;

e) Nível de estoque do kit amortecedor:

$200-98+22 \cdot 1,233 \approx 129$ unidades.

Realizada a correção na disponibilidade dos produtos, realizou-se uma segunda simulação, cujo relatório é esquematizado na Figura .

Os resultados indicam que não houveram demandas não atendidas e o nível de estoque final dos produtos ficou próximo ao desvio-padrão do consumo da Tabela 2. 
Devido à grande disponibilidade dos itens nesta simulação, o deslocamento total dos balconistas aumentou em aproximadamente 1444 metros em relação à primeira simulação, totalizando 7699,6 metros.

Figura 8 - Relatório da segunda simulação do modelo Arena®.

\section{User Specified}

\section{Tally}

\begin{tabular}{lrrrr} 
Expression & Average & Half Width & $\begin{array}{r}\text { Minimum } \\
\text { Value }\end{array}$ & $\begin{array}{r}\text { Maximum } \\
\text { Value }\end{array}$ \\
\hline Deslocamento_Balconistas & 3928.44 & (Correlated) & 0.00 & 7699.60 \\
Estoque_Agua_Destilada & 179.52 & (Correlated) & 51.0000 & 310.00 \\
Estoque_Filtro_Oleo & 83.5020 & (Correlated) & 24.0000 & 137.00 \\
Estoque_Kit_Amortecedor & 72.2147 & (Correlated) & 19.0000 & 129.00 \\
Estoque_Oleo_Motor & 725.51 & (Correlated) & 81.0000 & 1425.00 \\
Estoque_Vela_Ignicao & 399.70 & (Correlated) & 101.00 & 705.00
\end{tabular}

\section{Counter}

\begin{tabular}{lr} 
Count & Value \\
\hline Pedidos_Sem_Estoque & 0.00
\end{tabular}

Fonte: Autores (2019)

\subsection{Correção dos pontos de estocagem}

Garantidos os níveis de serviço dos produtos em estudo, os pontos de estocagem destes produtos foram modificados utilizando os pontos alternativos da Tabela 5.

Para esse modelo, os produtos foram alocados de acordo com a demanda. Assim, os itens com maior frequência de pedidos foram posicionados nos pontos alternativos de menor distância, como mostrado na Tabela 10.

Tabela 10 - Novos pontos de estocagem dos produtos em análise.

\begin{tabular}{cccc}
\hline Produtos & Distância Inicial $(\mathrm{m})$ & Posição final & Distância final (m) \\
\hline Óleo de motor & 4,6 & ponto 3 & 3,8 \\
Vela de ignição & 6,6 & ponto 2 & 4,6 \\
Filtro de óleo & 5,2 & mesma posição & 5,2 \\
Água destilada & 0,6 & mesma posição & 0,6 \\
Kit amortecedor & 6,6 & ponto 4 & 5,5 \\
\hline
\end{tabular}

Fonte: Autores (2019)

Realizadas as modificações, o relatório da terceira simulação é esquematizado na Figura . 
Figura 9 - Relatório da terceira simulação do modelo Arena®.

\section{User Specified}

Tally

\begin{tabular}{lcccc} 
Expression & Average & Half Width & $\begin{array}{c}\text { Minimum } \\
\text { Value }\end{array}$ & $\begin{array}{r}\text { Maximum } \\
\text { Value }\end{array}$ \\
\hline Deslocamento_Balconistas & 3223.16 & (Correlated) & 0.00 & 6329.80
\end{tabular}

Fonte: Autores (2019)

\section{Conclusões}

Sabe-se que existem vários métodos para determinação de estoque mínimo, como fórmulas utilizando em sua base o desvio padrão e o Lead Time do processo. Ao valer-se de um modelo de simulação Arena ${ }^{\circledR}$, o comportamento do estoque dos produtos mais relevantes da empresa Renoservice Autopeças pode ser avaliado com base no consumo de cada item. Todos estes dados são obtidos do banco de dados da empresa e em medições realizadas in loco.

Para avaliar o estoque desta forma, alterou-se o comportamento natural da empresa de atender de forma emergencial a uma demanda, simplesmente ignorando este atendimento para contabilizar quantas vezes isto ocorreu. Assim, demandas não atendidas são representadas por estoques negativos.

Os níveis de estoque obtidos para os produtos relevantes foram satisfatórios, visto que não houveram demandas não atendidas para o modelo de simulação em análise e a quantidade de produtos em estoque estão compatíveis com a variação de demanda verificada para cada item, considerando o grau de atendimento desejado pelo proprietário.

Foram selecionados e simulados os pontos de estocagem de cada produto de acordo com frequência de pedidos de cada item, possibilitando identificar as alocações de menor distância ao balcão. Desse modo, o deslocamento total - incialmente em 7699,6 metros - foi reduzido em aproximadamente 1370 metros, satisfazendo o objetivo de definir os pontos de estocagem adequados.

Ainda sobre o modelo Arena ${ }^{\circledR}$, é possível perceber que ele traz para a empresa benefícios, pois simula de forma virtual e muito próxima da realidade casos que poderiam trazer altos custos para a empresa, visto que mudanças seriam planejadas e recursos ocupados, como funcionários e espaço físico para realizá-las. 
Este modelo auxilia também na reposição do estoque, visto que as quantidades planejadas para cada mês deve ser a diferença do que ficou em estoque e o valor mínimo definido na simulação. Por fim, como sugestão de trabalho futuro, é possível estipular períodos de reposições, ao ser mapeado exatamente o momento em que faltou o produto, por meio de um submodelo dedicado à avaliação dos itens e programação da reposição do estoque antes deste atingir a margem de segurança. 


\section{REFERÊNCIAS}

BALLOU, Ronald H. Gerenciamento da cadeia de suprimentos: planejamento, organização e logística empresarial. Porto Alegre: Bookman, 2006.

FREITAS FILHO, P. J. Introdução à Modelagem e Simulação de Sistemas: com aplicações em Arena. 2. ed. Visual Books, 2008.

KELTON, W. D.; SADOWSKI, R. P.; STURROCK, D. T. Simulation with ARENA. 4. ed. New York: McGraw-Hill, 2007.

KOTLER, Philip. Administração de Marketing. 10. ed. São Paulo: Novo Milênio, 2000.

LAMBERT, D. M. Administração estratégica da logística. São Paulo: Vantine Consultoria, 1998.

MARTINS, Petrônio G; LAUGENI, Fernando Piero. Administração da Produção. 2 ed. São Paulo: Saraiva, 2005.

PARAGON. Introdução à simulação com Arena. Apostila do Curso Arena. ENEGEP, 2005.

POZO, Hamilton. Administração de recursos materiais e patrimoniais: uma abordagem logística. 6. ed. São Paulo: Atlas, 2010.

PRADO, D. S. Teoria das filas e da simulação. 3. ed. Belo Horizonte: INDG, 2003.

SANTOS, Marcos et al. Simulation of Operation of An Integrated Information for Emergency Pre-Hospital Care in Rio de Janeiro Municipality. Procedia Computer Science. ITQM 2015. Volume 55. p. 931-938. 2015. Disponível em:

https://www.sciencedirect.com/science/article/pii/S1877050915015860. Acesso em: 06 de mar. de 2019.

SLACK, Nigel et al. Administração da Produção. 4. ed. São Paulo: Atlas, 2015.

VIANA, João José. Administração de materiais: um Enfoque Prático. 1. ed. São Paulo: Editora Atlas, 2002.

YIN, Robert K. Estudo de caso: planejamento e métodos. 2.ed. Porto Alegre: Bookman, 2001. 